\title{
Naringenin attenuates the release of pro-inflammatory mediators from lipopolysaccharide-stimulated BV2 microglia by inactivating nuclear factor- $\kappa B$ and inhibiting mitogen-activated protein kinases
}

\author{
HYE YOUNG PARK ${ }^{1,2}$, GI-YOUNG KIM ${ }^{3}$ and YUNG HYUN CHOI ${ }^{1,4}$
}

\author{
${ }^{1}$ Department of Biochemistry, Dongeui University College of Oriental Medicine, Busan 614-052; ${ }^{2}$ Department of \\ Pharmacy, Busan National University, Busan 609-735; ${ }^{3}$ Department of Marine Life Sciences, Jeju National University, \\ Jeju 690-756; ${ }^{4}$ Department of Biomaterial Control (BK21 Program), Graduate School and Blue-Bio Industry \\ Regional Innovation Center, Dongeui University, Busan 614-714, Republic of Korea
}

Received January 25, 2012; Accepted March 23, 2012

DOI: 10.3892/ijmm.2012.979

\begin{abstract}
Naringenin, one of the most abundant flavonoids in citrus fruits and grapefruits, has been reported to exhibit anti-inflammatory and antitumor activities. However, the cellular and molecular mechanisms underlying the naringenin anti-inflammatory activity are poorly understood. In this study, we conducted an investigation of the inhibitory effects of naringenin on the production of lipopolysaccharide (LPS)induced pro-inflammatory mediators in BV2 microglial cells. We found that pre-treatment with naringenin prior to treatment with LPS significantly inhibited excessive production of nitric oxide (NO) and prostaglandin $\mathrm{E}_{2}\left(\mathrm{PGE}_{2}\right)$ in a dose-dependent manner. The inhibition was associated with downregulation of inducible nitric oxide synthase (iNOS) and cyclooxygenase-2 (COX-2) expression. Naringenin also attenuated the production of pro-inflammatory cytokines and chemokines, including interleukin-1 $\beta$ (IL-1 $\beta$ ), tumor necrosis factor- $\alpha$ (TNF- $\alpha$ ) and monocyte chemoattractant protein-1 (MCP-1) by suppressing expression of mRNAs for these proteins. In addition, the molecular mechanism underlying naringenin-mediated attenuation in BV2 cells has a close relationship to suppressing translocation of the nuclear factor- $\kappa \mathrm{B}$ (NF- $\mathrm{\kappa B}) \mathrm{p} 65$ subunit into the nucleus and the phosphorylation of Akt and mitogen-activated protein kinases (MAPKs). These findings suggest that naringenin may provide neuroprotection through suppression of pro-inflammatory pathways in activated BV2 microglial cells.
\end{abstract}

\section{Introduction}

Microglia are glial cells that enter the brain early in embryogenesis and develop in parallel with the maturation of the

Correspondence to: Dr Yung Hyun Choi, Department of Biochemistry, Dongeui University College of Oriental Medicine, Busan 614-052, Republic of Korea

E-mail: choiyh@deu.ac.kr

Key words: naringenin, anti-inflammation, nuclear factor- $\kappa \mathrm{B}, \mathrm{Akt}$, mitogen-activated protein kinase nervous system. Under normal conditions, these microglia play a major role in host defense and tissue repair in the central nervous system (CNS) (1-3). However, in response to injury, infection or inflammation, microglia readily become activated and secrete neurotoxic and pro-inflammatory mediators, including nitric oxide $(\mathrm{NO})$, prostaglandin $\mathrm{E}_{2}\left(\mathrm{PGE}_{2}\right)$, reactive oxygen species (ROS) and pro-inflammatory cytokines such as interleukin-1 $\beta$ (IL-1 $\beta$ ), IL- 6 and tumor necrosis factor- $\alpha$ (TNF- $\alpha$ ) (4-6). Therefore, microglial activation appears to play a pivotal role in the initiation and progression of neurodegenerative diseases, including Alzheimer's disease (AD), Parkinson's disease (PD), cerebral ischemia, multiple sclerosis and trauma (7-9). Thus, regulating microglial activation and downregulation of pro-inflammatory mediators in microglia may have the therapeutic potential to reduce neuronal injury or death in neurodegenerative diseases.

Flavonoids are a diverse group of plant natural products synthesized from phenylpropanoid and acetate-derived precursors. They are becoming an important source of novel agents with pharmaceutical potential and have attracted a great deal of attention in recent years for their role in the prevention of chronic diseases (9-13). Among them, naringenin and its glycoside naringin are abundant in grapefruit and citrus fruits and juices $(14,15)$. Previous studies have shown that naringenin inhibits CYP3A4 activity and exhibits aorta dilatory, antioxidant, antiestrogenic, antiproliferative and antimetastatic effects (16-20). Recently, naringenin, but not naringin, has been reported to induce apoptosis in various human cancer cells and treatment with a similar dose showed no toxic effect on normal cells (21-25). Although numerous studies on the antioxidant and anticancer effects of naringenin have been reported, the cellular and molecular mechanisms underlying naringenin-induced anti-inflammatory effects are not clear.

In this study, we investigated the inhibitory effects of naringenin and the way in which it induces anti-inflammatory mechanisms in lipopolysaccharide (LPS)-stimulated inflammatory mediator production in murine BV2 microglia. As a result of our findings, we suggest that naringenin may be a candidate for use in treatment of various neurodegenerative disorders in the brain. 


\section{Materials and methods}

Cell culture. BV2 murine microglial cells were obtained from Professor I.W. Choi (Inje University, Busan, Republic of Korea). The cells were cultured in Dulbecco's modified Eagle's medium (DMEM; Gibco-BRL, Gaithersburg, MD) supplemented with $10 \%$ fetal bovine serum (FBS), $100 \mathrm{U} / \mathrm{ml}$ penicillin and $100 \mu \mathrm{g} / \mathrm{ml}$ streptomycin and were maintained in a humidified incubator with 5\% $\mathrm{CO}_{2}$. Naringenin (SigmaAldrich, St. Louis, MO) was dissolved in dimethyl sulfoxide (DMSO) and dilutions were made in DMEM. The final concentration of DMSO in the medium was $<0.05 \%$ (vol $/ \mathrm{vol}$ ) which showed no influence on cell growth. In all experiments, cells were pre-treated with the indicated concentrations of naringenin for $1 \mathrm{~h}$ before addition of LPS (Escherichia coli 026:B6; Sigma-Aldrich).

Cell viability assay. Cell viability was measured based on formation of blue formazan metabolized from colorless 3-(4,5-dimethylthiazol-2-yl)-2,5-diphenyltetrazolium bromide (MTT, Sigma-Aldrich) by mitochondrial dehydrogenases, which are active only in live cells. BV2 cells were plated into 24 -well plates at a density of $2 \times 10^{5}$ cells/well for $24 \mathrm{~h}$ and then washed. The cells incubated with various concentrations of naringenin were treated with or without $0.5 \mu \mathrm{g} / \mathrm{ml}$ LPS for $24 \mathrm{~h}$ and then incubated in $0.5 \mathrm{mg} / \mathrm{ml}$ MTT solution. Three hours later, the supernatant was removed and formation of formazan was measured at $540 \mathrm{~nm}$ using a microplate reader (26).

Measurement of NO production. The concentrations of NO in culture supernatants were determined as nitrite, a major stable product of NO, using the Griess reagent (Sigma-Aldrich). After cells $\left(5 \times 10^{5}\right.$ cells $\left./ \mathrm{ml}\right)$ were stimulated in 24 -well plates for $24 \mathrm{~h}, 100 \mu \mathrm{l}$ of each cultured medium was mixed with the same volume of the Griess reagent [ $1 \%$ sulfanilamide/ $0.1 \%$ $\mathrm{N}$-(1-naphthyl)-ethylenediamine dihydrochloride/2.5\% $\left.\mathrm{H}_{3} \mathrm{PO}_{4}\right]$. Nitrite levels were determined using an ELISA plate reader at $540 \mathrm{~nm}$ and nitrite concentrations were calculated by reference to a standard curve generated by known concentrations of sodium nitrite (27).

Measurement of $\mathrm{PGE}_{2}$ production. BV2 cells were incubated with naringenin in either the presence or absence of LPS $(0.5 \mu \mathrm{g} / \mathrm{ml})$ for $24 \mathrm{~h}$. Following the manufacturer's instructions, a volume of $100 \mu \mathrm{l}$ of culture-medium supernatant was collected for determination of $\mathrm{PGE}_{2}$ concentration by ELISA (Cayman Chemical, Ann Arbor, MI).

Reverse transcriptase-polymerase chain reaction. Total-RNA was isolated using TRIzol reagent (Invitrogen Life Technologies, Carlsbad, CA). Total-RNA $(1.0 \mu \mathrm{g})$ obtained from cells was primed with random hexamers to synthesize complementary DNA using M-MLV reverse transcriptase (Promega, Madison, WI) according to the manufacturer's instructions. Polymerase chain reaction (PCR) was performed for amplification of the inducible nitric oxide synthase (iNOS), cyclooxygenase- 2 (COX-2), IL- $1 \beta$, TNF- $\alpha$ and monocyte chemoattractant protein-1 (MCP-1) genes from the cDNA and glyceraldehyde-3-phosphate dehydrogenase (GAPDH) was used as an internal control. Conditions for the PCR reactions were $1 \mathrm{x}\left(94^{\circ} \mathrm{C}\right.$ for $\left.3 \mathrm{~min}\right) ; 35 \mathrm{x}\left(94^{\circ} \mathrm{C}\right.$ for $45 \mathrm{sec}, 58^{\circ} \mathrm{C}$ for $45 \mathrm{sec}$, and $72^{\circ} \mathrm{C}$ for $\left.1 \mathrm{~min}\right)$; and $1 \mathrm{x}\left(72^{\circ} \mathrm{C}\right.$ for $\left.10 \mathrm{~min}\right)$. Amplification products obtained by PCR were electrophoretically separated on $1 \%$ agarose gel and visualized by $\mathrm{EtBr}$ staining.

Protein extraction and western blot analysis. For western blot analysis, cells were harvested and washed twice in PBS at $4^{\circ} \mathrm{C}$. Total cells lysates were lysed in lysis buffer [ $40 \mathrm{mM}$ Tris ( $\mathrm{pH}$ 8.0), $120 \mathrm{mM}, \mathrm{NaCl}, 0.5 \% \mathrm{NP}-40,0.1 \mathrm{mM}$ sodium orthovanadate, $2 \mu \mathrm{g} / \mathrm{ml}$ aprotinin, $2 \mu \mathrm{g} / \mathrm{ml}$ leupeptin and $100 \mu \mathrm{g} / \mathrm{ml}$ phenymethylsulfonyl fluoride]. The supernatants were collected and protein concentrations were then measured with protein assay reagents (Pierce Biotechnology, Inc., Rockford, IL). Equal amounts of protein extracts were denatured by boiling at $95^{\circ} \mathrm{C}$ for $5 \mathrm{~min}$ in sample buffer $(0.5 \mathrm{M}$ Tris-HCl, pH 6.8, 4\% SDS, 20\% glycerol, $0.1 \%$ bromophenol blue, $10 \% \beta$-mercaptoethanol) in a ratio of $1: 1$, subjected to $8-10 \%$ sodium dodecyl sulfate (SDS)-polyacrylamide gels and transferred to polyvinylidene difluoride membranes (Schleicher and Schuell Bioscience, Inc., Keene, NH) by electroblotting. The membranes were blocked with $5 \%$ non-fat dry milk in PBS with Tween-20 buffer (PBS-T) (20 mM Tris, $100 \mathrm{mM} \mathrm{NaCl}, \mathrm{pH} 7.5$ and $0.1 \%$ Tween-20) for $1 \mathrm{~h}$ at room temperature. Membranes were then incubated overnight at $4^{\circ} \mathrm{C}$ with the primary antibodies, probed with enzyme-linked secondary antibodies and visualized using an enhanced chemiluminescence (ECL) kit (Amersham Life Science, Arlington Heights, IL) according to the manufacturer's instructions. In a parallel experiment, nuclear proteins were prepared using the NE-PER nuclear extraction reagent (Pierce Biotechnology, Inc.) according to the manufacturer's protocol.

Enzyme immunosolvent assay (ELISA). The levels of IL-1 $\beta$, TNF- $\alpha$ (R\&D Systems, Minneapolis, MN) and MCP-1 (BioLegend, San Diego, CA) were measured by the ELISA kits according to the manufacturer's instructions. Briefly, BV2 cells $\left(5 \times 10^{5}\right.$ cells $\left./ \mathrm{ml}\right)$ were plated in $24-w e l l$ plates and pre-treated with the indicated concentrations of naringenin for $1 \mathrm{~h}$ before treatment of $0.5 \mu \mathrm{g} / \mathrm{ml}$ LPS for $24 \mathrm{~h}$. One hundred microliters of culture-medium supernatants were collected for determination of IL-1 $\beta$, TNF- $\alpha$ and MCP-1 concentration by ELISA (28).

Electrophoretic mobility shift assay (EMSA). DNA-protein binding assays were carried out with nuclear extract. Synthetic

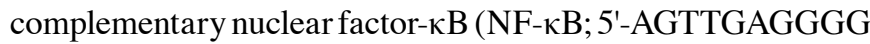
ACTTTCCCAGGC-3') binding oligonucleotides (Santa Cruz Biotechnology, Inc., Santa Cruz, CA) were 3'-biotinylated using the biotin 3'-end DNA labeling kit (Pierce Biotechnology, Inc.) according to the manufacturer's instructions and annealed for $30 \mathrm{~min}$ at room temperature. The reaction mixture was electrophoretically separated on a $4 \%$ polyacrylamide gel in $0.5 \mathrm{X}$ Tris-borate buffer and transferred to a nylon membrane. The transferred DNAs were cross-linked to the membrane at $120 \mathrm{~mJ} / \mathrm{cm}^{2}$. Horseradish peroxidase-conjugated streptavidin was used according to the manufacturer's instructions to detect the transferred DNA.

$N F-\kappa B$ luciferase assay. A total of $1 \times 10^{6} \mathrm{BV} 2$ cells were transfected with $2 \mu \mathrm{g} \mathrm{NF}-\kappa \mathrm{B}-l u c i f e r a s e$ reporter plasmids (BD Biosciences, San Jose, CA) using lipofectamine according to the 

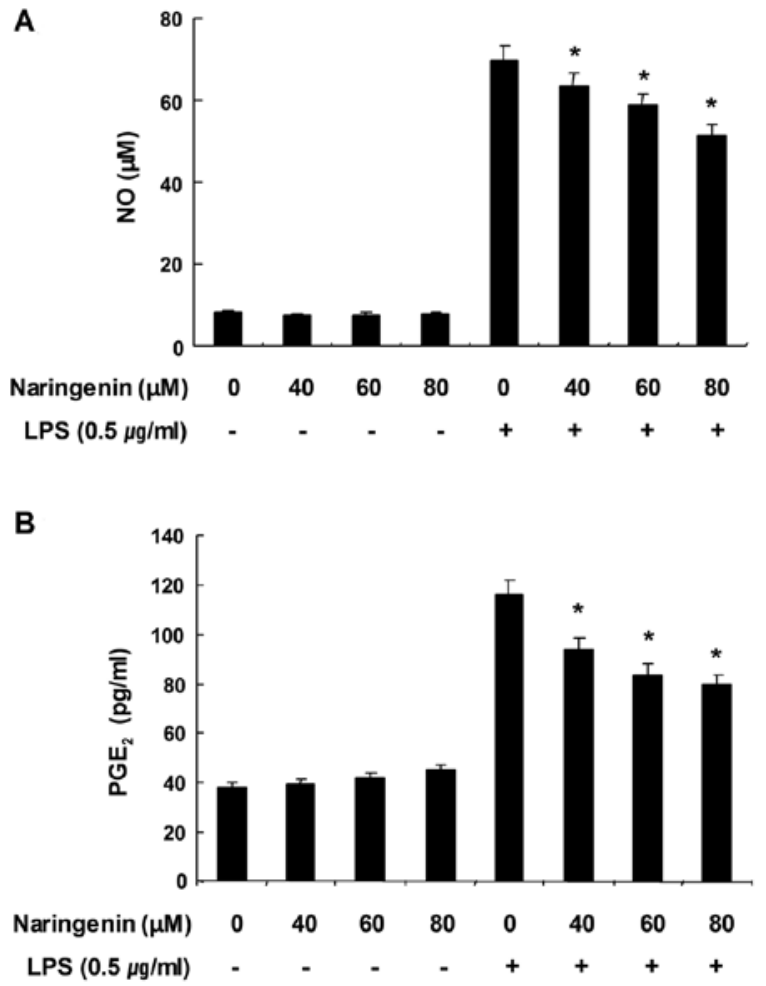

Figure 1. Inhibition of $\mathrm{NO}$ and $\mathrm{PGE}_{2}$ production by naringenin in LPS-stimulated $\mathrm{BV} 2$ microglia. BV2 cells were pre-treated with various concentrations of naringenin for $1 \mathrm{~h}$ prior to incubation with LPS $(0.5 \mu \mathrm{g} / \mathrm{ml})$ for $24 \mathrm{~h}$. (A) Nitrite content was measured using the Griess reaction. (B) Sample treatment conditions were identical to those described for (A) and a commercially available ELISA kit was used for measurement of $\mathrm{PGE}_{2}$ in the resulting supernatants Each value indicates the mean $\pm \mathrm{SD}$ and is representative of results obtained from 3 independent experiments. ${ }^{*} \mathrm{P}<0.05$ indicates a significant difference from the value obtained for cells treated with LPS in the absence of naringenin.

manufacturer's protocol (Gibco-BRL). After incubating with DNA-lipofectamine mixtures, the cells were pre-incubated in the presence or absence of naringenin before being stimulated with LPS for $6 \mathrm{~h}$. Cells were then washed twice with PBS and lysed with reporter lysis buffer (Promega). After vortexing and centrifugation at $12,000 \mathrm{x} \mathrm{g}$ for $1 \mathrm{~min}$ at $4^{\circ} \mathrm{C}$, the supernatant was stored at $-70^{\circ} \mathrm{C}$ for the luciferase assay. After $20 \mu \mathrm{l}$ of the cell extract was mixed with $100 \mu \mathrm{l}$ of the luciferase assay reagent at room temperature, the mixture was measured a microplate luminometer LB96V (Perkin-Elmer, Foster City, CA) (29).

Statistical analysis. Data values represent the means \pm SD. Statistical significance was determined using analysis of variance, followed by Student's t-test. A value of $\mathrm{P}<0.05$ was accepted as statistically significant.

\section{Results}

Naringenin attenuates $N O$ and $P G E_{2}$ production in LPS-stimulated BV2 microglia. To determine levels of NO production, we measured nitrite released into the culture medium using the Griess reagent. For this study, BV2 cells were pre-treated with various concentrations of naringenin for $1 \mathrm{~h}$ prior to stimulation with LPS. According to the NO detection assay, treatment with LPS alone resulted in higher NO production by cells as compared with that generated by the
A

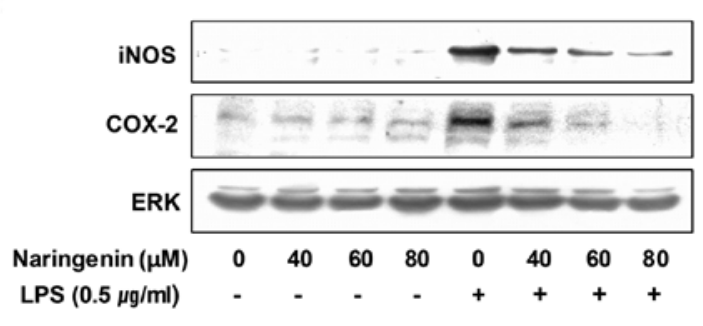

B

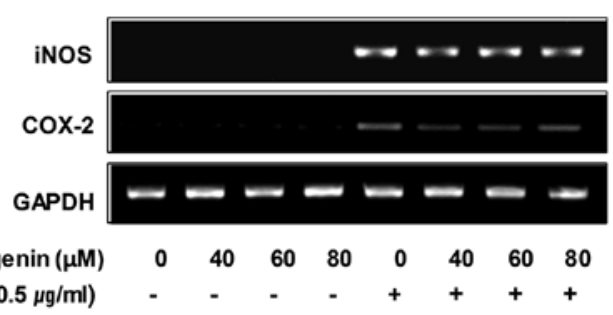

Figure 2. Inhibition of iNOS and COX-2 expression by naringenin in LPSstimulated BV2 microglia. (A) BV2 cells were pre-treated with naringenin $1 \mathrm{~h}$ prior to incubation with LPS $(0.5 \mu \mathrm{g} / \mathrm{ml})$ for $24 \mathrm{~h}$. Cell lysates were then prepared and western blot analysis was performed using antibodies specific for murine iNOS and COX-2. (B) After LPS treatment for $6 \mathrm{~h}$, total-RNA was prepared for RT-PCR analysis of iNOS and COX-2 gene expression in LPSstimulated BV2 microglia. ERK and GAPDH were used as internal controls for western blot analysis and RT-PCR assays, respectively. The experiment was repeated 3 times and similar results were obtained.

control. However, pre-treatment with naringenin significantly repressed the levels of NO production in LPS-stimulated BV2 cells in a concentration-dependent manner (Fig. 1A). $\mathrm{PGE}_{2}$ is another important inflammatory mediator. We evaluated the effects of naringenin on $\mathrm{PGE}_{2}$ production in LPS-stimulated BV2 cells. As indicated in Fig. 1B, treatment of BV2 cells with LPS alone resulted in a marked increase in $\mathrm{PGE}_{2}$ release in comparison to untreated controls. However, naringenin inhibited LPS-induced $\mathrm{PGE}_{2}$ production in a concentrationdependent manner. These results suggest that pre-treatment with naringenin suppresses LPS-mediated expression of proinflammatory mediators. In order to exclude cytotoxic effects of naringenin in BV2 microglia, we evaluated the viability of BV2 cells incubated with or without $0.5 \mu \mathrm{g} / \mathrm{ml}$ LPS in the absence or presence of naringenin using MTT assays. Concentrations (40-80 $\mu \mathrm{M})$ used for inhibition of NO and $\mathrm{PGE}_{2}$ production did not affect cell viability (data not shown), confirming that inhibition of $\mathrm{NO}$ and $\mathrm{PGE}_{2}$ production in LPS-stimulated BV2 cells was not due to a cytotoxic action of naringenin.

Naringenin decreases expression of LPS-stimulated iNOS and COX-2 mRNA and protein. We carried out RT-PCR and western blot analyses to determine whether inhibition of NO and $\mathrm{PGE}_{2}$ production were associated with decreased levels of iNOS and COX-2 expression. As shown in Fig. 2, iNOS and COX-2 mRNA levels were detectable $6 \mathrm{~h}$ after LPS treatment, whereas the protein levels of these enzymes were detected in whole cell lysates $24 \mathrm{~h}$ after LPS treatment. However, naringenin markedly decreased both mRNA and protein levels for iNOS and COX-2. The results suggest that naringenin-induced reductions in the expression of iNOS and COX-2 were the cause of the inhibition of $\mathrm{NO}$ and $\mathrm{PGE}_{2}$ production. 

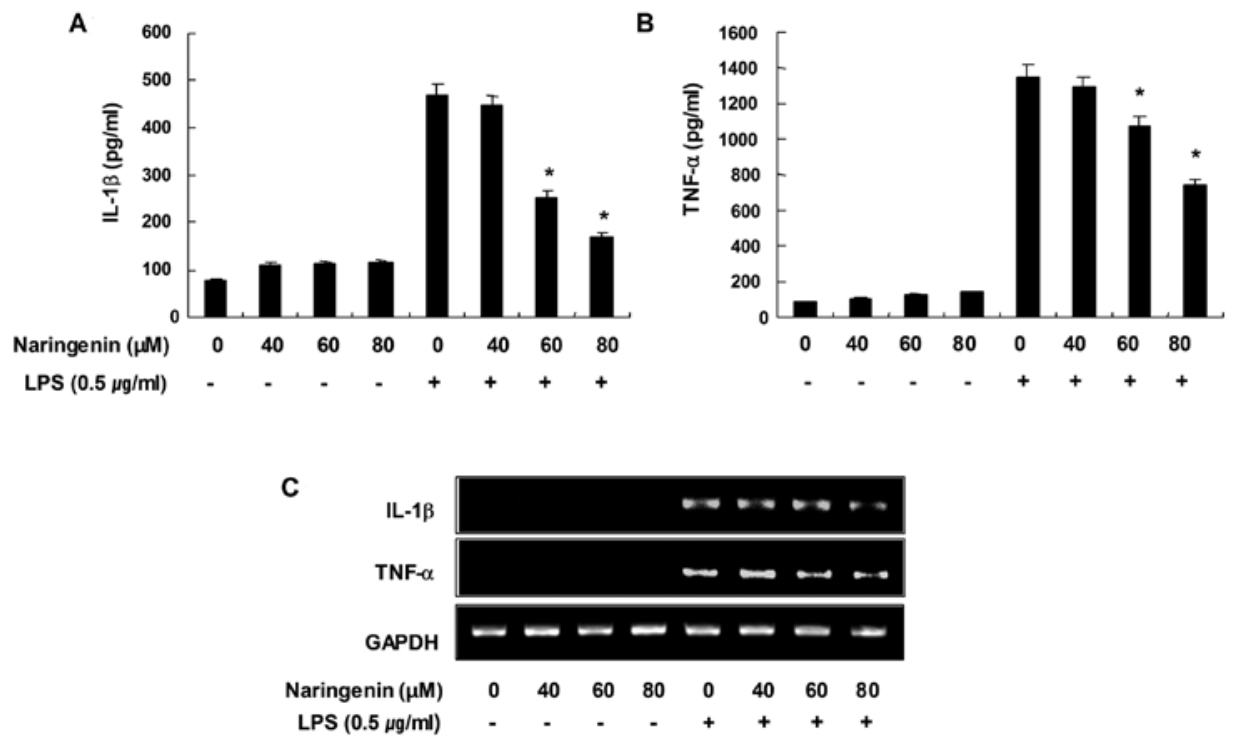

Figure 3. Effects of naringenin on LPS-stimulated IL-1 $\beta$ and TNF- $\alpha$ production and expression in BV2 microglia. (A and B) BV2 cells were pre-treated with naringenin for $1 \mathrm{~h}$ prior to LPS treatment $(0.5 \mu \mathrm{g} / \mathrm{ml})$. After incubation for $24 \mathrm{~h}$, levels of (A) IL-1 $\beta$ and (B) TNF- $\alpha$ present in the supernatants were measured. Each value indicates the mean \pm SD and is representative of results obtained from 3 independent experiments. * $\mathrm{P}<0.05$ indicates a significant difference from the value obtained for cells treated with LPS in the absence of naringenin. (C) Cells were pre-treated with naringenin for $1 \mathrm{~h} \mathrm{prior}$ to LPS treatment $(0.5 \mu \mathrm{g} / \mathrm{ml})$ and total-RNA was isolated $6 \mathrm{~h}$ after LPS treatment. RT-PCR was performed for determination of the levels of IL-1 $\beta$ and TNF- $\alpha$ mRA. The experiment was repeated 3 times and similar results were obtained.

A

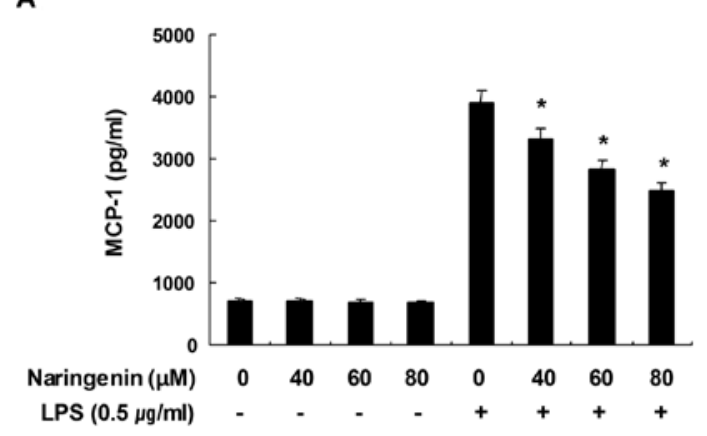

B

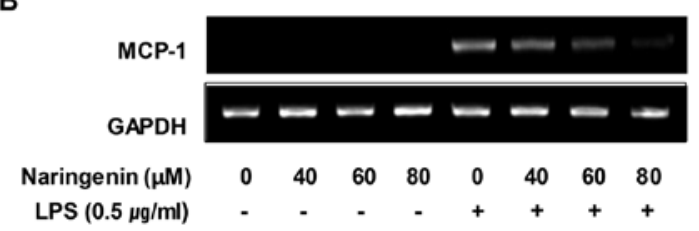

Figure 4. Effects of naringenin on MCP-1 production in LPS-stimulated BV2 microglia. BV2 cells were pre-treated with the indicated doses of naringenin for $1 \mathrm{~h}$ before LPS treatment $(0.5 \mu \mathrm{g} / \mathrm{ml})$ and total-RNA and supernatants were isolated at 6 or $24 \mathrm{~h}$ after LPS treatment, respectively. (A) Following incubation for $24 \mathrm{~h}$ and centrifugation, supernatants were isolated and the amounts of MCP-1 were measured by ELISA kits according to the manufacturer's instructions. Each value indicates the mean $\pm \mathrm{SD}$ and is representative of results obtained from 3 independent experiments. ${ }^{*} \mathrm{P}<0.05$ indicates a significant difference from cells treated with LPS in the absence of naringenin. (B) Following incubation for $6 \mathrm{~h}$, levels of MCP-1 mRNA were determined by RT-PCR. The experiment was repeated 3 times and similar results were obtained.

Naringenin suppresses induction of inflammatory cytokines in LPS-stimulated BV2 microglia. We next determined whether or not naringenin suppresses production of pro-inflammatory cytokines such as IL- $1 \beta$ and TNF- $\alpha$. For this study, BV 2 cells were incubated with naringenin in the absence or presence of LPS for $24 \mathrm{~h}$ and cytokine levels were evaluated in the culture supernatants. As shown in Fig. 3A and B, the levels of IL-1 $\beta$ and TNF- $\alpha$ were markedly increased in the culture media of LPS-stimulated BV2 microglia. However, pre-treatment with naringenin resulted in a significant decrease in the release of these pro-inflammatory cytokines in a concentration-dependent manner. In a parallel experiment using RT-PCR, we studied the effects of naringenin on LPS-induced IL-1 $\beta$ and TNF- $\alpha$ mRNA expression. As shown in Fig. 3B, IL-1 $\beta$ and TNF- $\alpha$ mRNA transcription also decreased following naringenin treatment. These results suggest that naringenin suppresses pro-inflammatory cytokine production through alteration of the transcription levels of IL-1 $\beta$ and TNF- $\alpha$ in activated microglia.

Naringenin attenuates $M C P-1$ protein and $m R N A$ in $L P S$-stimulated BV2 microglia. We determined the effects of naringenin on production of chemokine MCP-1. As shown in Fig. 4A, naringenin alone had no effect on the production of MCP-1 in BV2 cells, but the levels of MCP-1 were markedly increased in the culture media of LPS-stimulated BV2 microglia. However, pre-treatment with naringenin resulted in a concentration-dependent decrease of MCP-1 production, which was associated with a reduction in LPS-mediated increases in MCP-1 mRNA levels. These results also indicate that naringenin regulates production of MCP-1 at the transcriptional level.

Naringenin blocks $N F-\kappa B$ in LPS-stimulated BV2 microglia. Because activation of NF- $\kappa \mathrm{B}$ is the key event for the induction of all major pro-inflammatory mediators, we next investigated whether naringenin modulates the activation of $\mathrm{NF}-\kappa \mathrm{B}$ in BV2 microglia in response to LPS. As shown in Fig. 5, immunoblotting indicated that stimulation of cells with LPS induced the degradation of $\mathrm{I} \kappa \mathrm{B} \alpha$ and the translocation of the $\mathrm{NF}-\kappa \mathrm{B}$ 


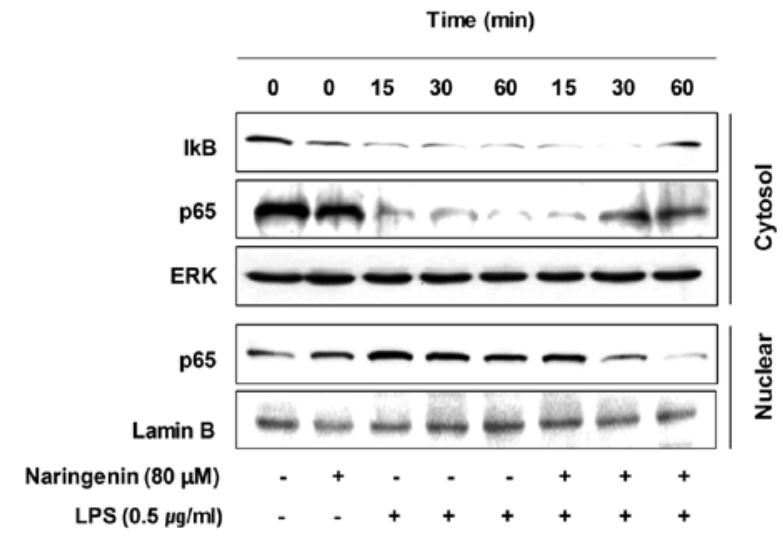

Figure 5. Effects of naringenin on LPS-induced NF- $\kappa \mathrm{B}$ translocation and ІкB degradation in BV2 microglia. Cells were treated with naringenin for $1 \mathrm{~h}$ before LPS treatment $(0.5 \mu \mathrm{g} / \mathrm{ml})$ for the indicated times. Nuclear and cytosolic proteins were subjected to $10 \%$ SDS-polyacrylamide gels followed by western blot

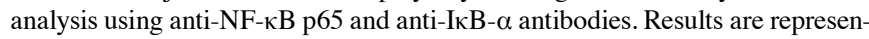
tative of those obtained from 3 independent experiments. ERK and lamin B were used as internal controls for nuclear and cytosolic fractions, respectively.

A

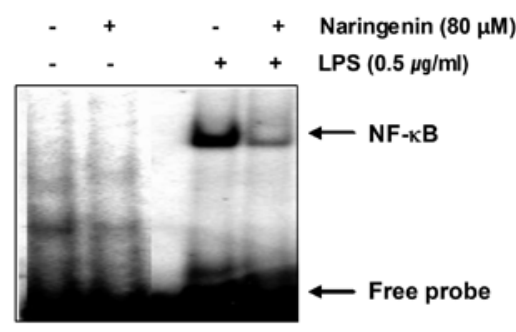

B

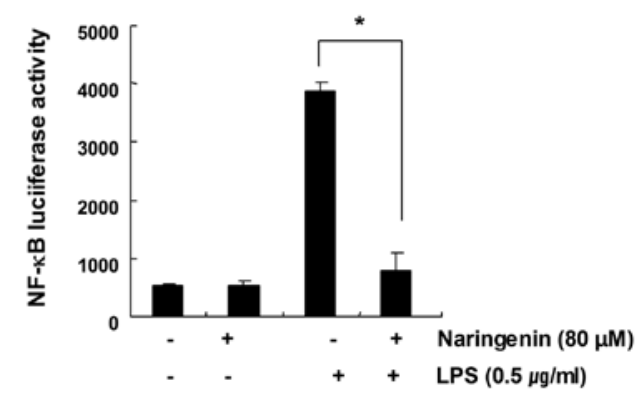

Figure 6. Effects of naringenin on NF- $\mathrm{BB}$ activation in LPS-stimulated BV2 microglia. (A) BV2 cells were pre-incubated with naringenin $(80 \mu \mathrm{M})$ for $1 \mathrm{~h}$ before stimulation of LPS $(0.5 \mu \mathrm{g} / \mathrm{ml})$ for $30 \mathrm{~min}$. Then, the nuclear extracts were assayed for NF- $\mathrm{\kappa B}$ activity by EMSA as described in Materials and methods. The experiment was repeated 3 times and similar results were obtained each time. (B) Transfected BV2 microglia were pre-treated with naringenin for $1 \mathrm{~h}$ and then stimulated with LPS for $6 \mathrm{~h}$. NF-kB activity was expressed as luciferase activities. Each value indicates the mean \pm SD and is representative of results obtained from 3 independent experiments. "P $<0.05$ indicates a significant difference from cells treated with LPS in the absence of naringenin.

p65 subunit from the cytosol to the nucleus. LPS-induced I $\mathrm{B}$ degradation was inhibited after $30 \mathrm{~min}$ of exposure to naringenin. Also, naringenin inhibited nuclear translocation of the NF- $\mathrm{kB}$ p65 protein. According to the EMSA assay, LPS treatment caused a significant increase in the DNA-binding activity of NF- $\mathrm{KB}$ (Fig. 6A). In contrast, treatment with naringenin significantly suppressed the LPS-induced DNA binding activity of NF- $\mathrm{\kappa B}$. We next tried to confirm inhibition

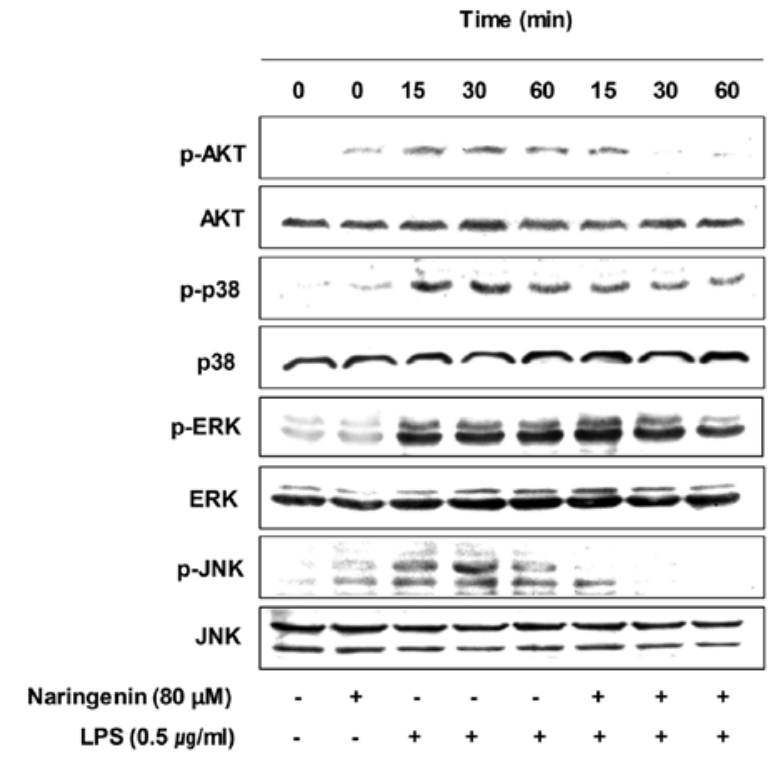

Figure 7. Effects of naringenin on AKT and MAPKs activation induced by LPS in BV2 microglia. BV2 cells were treated with the indicated concentrations of naringenin for $1 \mathrm{~h}$ prior to LPS $(0.5 \mu \mathrm{g} / \mathrm{ml})$ treatment for the indicated times. Total protein was subjected to $10 \%$ SDS-polyacrylamide gels, followed by western blot analysis using the indicated antibodies. Proteins were visualized using an ECL detection system.

of LPS-induced NF- $\kappa \mathrm{B}$ activation by naringenin by luciferase assay. For this study, BV2 cells transfected with NF-кBluciferase reporter plasmids were pre-treated with naringenin for $1 \mathrm{~h}$ and stimulated with LPS for $6 \mathrm{~h}$ and then luciferase activity was measured. As shown in Fig. 5B, LPS significantly enhanced NF- $\kappa$ B activity up to 8-fold over the basal level, while naringenin significantly inhibited LPS-induced NF- $\kappa B$ activity. Taken together, the above findings demonstrate involvement of the NF- $\mathrm{kB}$ pathway in the anti-inflammatory effect of naringenin in LPS-stimulated BV2 cells.

Naringenin reduces LPS-induced phosphorylation of Akt and MAPKs in LPS-stimulated BV2 microglia. To investigate other intracellular mechanisms responsible for the inhibitory effect of naringenin on inflammatory mediators, we examined the effect of naringenin on Akt and mitogen-activated protein kinases (MAPKs) signaling pathways. As shown in Fig. 7, phosphorylation of Akt was increased within 15 min after LPS stimulation and naringenin pre-treatment resulted in significant blockage of LPS-induced Akt phosphorylation. Furthermore, stimulation of BV2 cells with LPS led to rapid activation of p38MAPK, ERK and JNK, with the peak levels of each phospho-MAPK occurring 15-60 min after addition of LPS. However, naringenin pre-treatment significantly inhibited phosphorylation of MAPKs in LPS-stimulated BV2 microglia (Fig. 7). This finding suggests that naringenin is capable of disrupting key signal transduction pathways such as Akt and MAPKs that are activated by LPS in BV2 microglia; the disruption prevents production of pro-inflammatory mediators.

\section{Discussion}

In this study, we demonstrated that naringenin in activated BV2 microglial cells inhibits LPS-induced production of 
pro-inflammatory mediators such as $\mathrm{NO}$ and $\mathrm{PGE}_{2}$, cytokines, including TNF- $\alpha$ and IL-1 $\beta$, and the chemokine MCP-1. These effects were accompanied by downregulation of NF- $\kappa \mathrm{B}$ activity and inactivation of Akt and MAPK signaling pathways. In theory, downregulators of these inflammatory molecules have been considered as candidate anti-inflammatory drugs to alleviate progression of neurodegenerative diseases caused by activation of microglia (30-32). Therefore, the inhibition of pro-inflammatory molecules by naringenin shown in this study could play a beneficial role in the treatment of neurodegenerative diseases.

$\mathrm{NO}, \mathrm{PGE}_{2}$ and pro-inflammatory cytokines and chemokines, such as TNF- $\alpha$, IL- 6 , IL- $1 \beta$ and MCP- 1 , have been implicated as important mediators in the process of inflammation. Several lines of evidence have shown that the activation of microglia induced by CNS injury or infection is associated with neurodegenerative disorders and the release of $\mathrm{NO}$ and $\mathrm{PGE}_{2}$, and with subsequent release of pro-inflammatory cytokines and chemokines (4-6). Previously, many studies have shown that expression of COX-2 and iNOS, key enzymes for $\mathrm{NO}$ and $\mathrm{PGE}_{2}$, are upregulated in activated glial cells. Also, pro-inflammatory cytokines activate the transcription of COX-2 and iNOS genes, and anti-inflammatory drugs may also effectively reduce $\mathrm{NO}$ and $\mathrm{PGE}_{2}$ production (1,4-6). In this study, we demonstrate that naringenin treatment significantly inhibits $\mathrm{NO}$ and $\mathrm{PGE}_{2}$ production in LPS-stimulated BV2 microglia. The inhibitory effects of naringenin attenuated the expression iNOS and COX-2 mRNA and protein, indicating that the effect of naringenin occurs at the transcriptional level. The present data also indicate that naringenin inhibits the production of pro-inflammatory cytokines and chemokines such as TNF- $\alpha$, IL-1 $\beta$ and MCP-1. Thus, the inhibitory actions of naringenin on the production of inflammatory mediators occurs at the transcriptional level.

The transcription factor NF- $\mathrm{KB}$ is a primary regulator of genes that are involved in production of pro-inflammatory cytokines and enzymes involved in the inflammatory process (33-35). In addition, involvement of the phosphoinositide 3-kinase (PI3K)/Akt pathway in the expression of inflammatory mediators in microglia through activation of NF- $\mathrm{KB}$ has been shown $(36,37)$. As a result of its key role in several pathologic conditions, NF- $\mathrm{KB}$ is a major drug target in a variety of diseases. The blockade of NF- $\mathrm{KB}$ transcriptional activity in microglial is also known to suppress expression of iNOS, COX-2, pro-inflammatory cytokines and chemokines including TNF- $\alpha$, IL-1 $\beta$ and MCP-1 (38-40). Therefore, many putative anti-inflammatory therapies seek to block $\mathrm{NF}-\kappa \mathrm{B}$ activity. We demonstrated that naringenin causes marked blockage of LPS-induced I $\kappa$ B- $\alpha$ degradation, and of $\mathrm{NF}-\kappa \mathrm{B}$ translocation and transcriptional activity. Our findings suggest that downregulation of pro-inflammatory mediators by naringenin is due to inhibition of the NF- $\kappa B$ pathway. Furthermore, naringenin significantly inhibited Akt activation in LPS-stimulated BV2 microglia, indicating that naringenin inhibits LPS-induced NF- $\mathrm{kB}$ activation via inactivation of the PI3K/AKT signaling pathway.

Involvement of various intracellular signaling pathways, such as MAPKs, in inflammatory mediator induction has been reported (41-44). LPS is also known to activate a series of MAPKs such as ERK, p38MAPK and JNK in microglial cells
(45). Therefore, experiments were performed to determine whether naringenin tightly regulates expression of MAPKs to induce anti-inflammatory effects in LPS-stimulated BV2 microglia. The present study indicates that naringenin is a potent inhibitor of MAPKs expression induced by LPS stimulation in BV2 microglia. Although, further studies are needed to validate roles for MAPKs in changes in various inflammatory mediators in microglia, the present results suggest that the anti-inflammatory effects of naringenin are associated with inhibition of the MAPKs signaling pathway.

In conclusion, the results presented in this study, demonstrate that naringenin inhibits LPS-induced $\mathrm{NO}$ and $\mathrm{PGE}_{2}$ production by suppressing iNOS and COX-2 mRNA and protein expression in BV2 microglial cells. Naringenin also inhibits the production of pro-inflammatory cytokines and chemokines (TNF- $\alpha$, IL-1 $\beta$ and MCP-1) by suppressing their transcriptional activity. The inhibitory action of naringenin was mediated by prevention of NF- $\mathrm{KB}$ activation and by inhibition of IкB-degradation, which is accompanied by the blocking of PI3K/Akt and MAPKs pathways. As a result of the findings presented in this study, we suggest that naringenin may provide an effective treatment for many inflammatory and neurodegenerative diseases.

\section{Acknowledgements}

This study was supported by the R\&D program of MKE/KEIT (10040391, Development of functional food materials and device for prevention of aging-associated muscle function decrease).

\section{References}

1. Gebicke-Haerter PJ: Microglia in neurodegeneration: molecular aspects. Microsc Res Tech 54: 47-58, 2001.

2. Mosley RL, Benner EJ, Kadiu I, Thomas M, Boska MD, Hasan K, Laurie $\mathrm{C}$ and Gendelman HE: Neuroinflammation, oxidative stress and the pathogenesis of Parkinson's disease. Clin Neurosci Res 6: 261-281, 2006.

3. Reynolds A, Laurie C, Mosley RL and Gendelman HE: Oxidative stress and the pathogenesis of neurodegenerative disorders. Int Rev Neurobiol 82: 297-325, 2007.

4. Perry VH, Nicoll JA and Holmes C: Microglia in neurodegenerative disease. Nat Rev Neurol 6: 193-201, 2010.

5. Rivest S: Molecular insights on the cerebral innate immune system. Brain Behav Immun 17: 13-19, 2003.

6. Das S and Basu A: Inflammation: a new candidate in modulating adult neurogenesis. J Neurosci Res 86: 199-1208, 2008.

7. Long-Smith CM, Sullivan AM and Nolan YM: The influence of microglia on the pathogenesis of Parkinson's disease. Prog Neurobiol 89: 277-287, 2009.

8. Lull ME and Block ML: Microglial activation and chronic neurodegeneration. Neurotherapeutics 7: 354-365, 2010.

9. Stadelmann C: Multiple sclerosis as a neurodegenerative disease: pathology, mechanisms and therapeutic implications. Curr Opin Neurol 24: 224-229, 2011.

10. Dixon RA and Steele CL: Flavonoids and isoflavonoids - a gold mine for metabolic engineering. Trends Plant Sci 4: 394-400, 1999.

11. Chen D, Chen MS, Cui QC, Yang H and Dou QP: Structureproteasome-inhibitory activity relationships of dietary flavonoids in human cancer cells. Front Biosci12: 1935-1945, 2007.

12. Le Marchand L, Murphy SP, Hankin JH, Wilkens LR and Kolonel LN: Intake of flavonoids and lung cancer. J Natl Cancer Inst 92: 154-160, 2000.

13. Szejtli J and Szente L: Elimination of bitter, disgusting tastes of drugs and foods by cyclodextrins. Eur J Pharm Biopharm 61: 115-125, 2005.

14. Rouseff RL: Liquid chromatographic determination of naringin and neohesperidin as a detector of grapefruit juice in orange juice. J Assoc Off Anal Chem 71: 798-802, 1988. 
15. Hare JT and Elliott DP: Grapefruit juice and potential drug interactions. Consult Pharm 18: 466-472, 2003.

16. Ruh MF, Zacharewski T, Connor K, Howell J, Chen I and Safe S: Naringenin: a weakly estrogenic bioflavonoid that exhibits antiestrogenic activity. Biochem Pharmacol 50: 1485-1493, 1995.

17. Knowles LM, Zigrossi DA, Tauber RA, Hightower C and Milner JA: Flavonoids suppress androgen-independent human prostate tumor proliferation. Nut Cancer 38: 116-122, 2000

18. Galati G, Moridani MY, Chan TS and O'Brien PJ: Peroxidative metabolism of apigenin and naringenin versus luteolin and quercetin: glutathione oxidation and conjugation. Free Radic Biol Med 30: 370-382, 2001.

19. van Meeuwen JA, Korthagen N, de Jong PC, Piersma AH and van den Berg M: (Anti)estrogenic effects of phytochemicals on human primary mammary fibroblasts, MCF-7 cells and their co-culture. Toxicol Appl Pharmacol 221: 372-383, 2007.

20. Galluzzo P, Ascenzi P, Bulzomi P and Marino M: The nutritional flavanone naringenin triggers antiestrogenic effects by regulating estrogen receptor $\alpha$-palmitoylation. Endocrinology 149: 2567-2575, 2008.

21. Chen YC, Shen SC and Lin HY: Rutinoside at C7 attenuates the apoptosis-inducing activity of flavonoids. Biochem Pharmacol 66: 1139-1150, 2003.

22. Kanno S, Tomizawa A, Hiura T, Osanai Y, Shouji A, Ujibe M, Ohtake T, Kimura K and Ishikawa M: Inhibitory effects of naringenin on tumor growth in human cancer cell lines and sarcoma S-180-implanted mice. Biol Pharm Bull 28: 527-530, 2005.

23. Kanno S, Tomizawa A, Ohtake T, Koiwai K, Ujibe M and Ishikawa M: Naringenin-induced apoptosis via activation of NF-kappaB and necrosis involving the loss of ATP in human promyeloleukemia HL-60 cells. Toxicol Lett 166: 131-139, 2006.

24. Park JH, Jin CY, Lee BK, Kim GY, Choi YH and Jeong YK: Naringenin induces apoptosis through downregulation of Akt and caspase- 3 activation in human leukemia THP-1 cells. Food Chem Toxicol 46: 3684-3690, 2008.

25. Wang BD, Yang ZY, Wang Q, Cai TK and Crewdson P: Synthesis, characterization, cytotoxic activities, and DNA-binding properties of the La(III) complex with Naringenin Schiff-base. Bioorg Med Chem 14: 1880-1888, 2006.

26. Divsalar A, Saboury AA, Ahadi L, Zemanatiyar E and MansouriTorshizi H: Investigation of effects of newly synthesized Pt(II) complex against human serum albumin and leukemia cell line of K562. BMB Rep 43: 766-771, 2010.

27. Woo A, Min B and Ryoo S: Piceatannol-3'-O-beta-Dglucopyranoside as an active component of rhubarb activates endothelial nitric oxide synthase through inhibition of arginase activity. Exp Mol Med 42: 524-532, 2010.

28. Choi JH, Park JG, Jeon HJ, Kim MS, Lee MR, Lee MN, Sonn S, Kim JH, Lee MH, Choi MS, et al: 5-(4-Hydroxy2,3,5-trimethylbenzylidene) thiazolidine-2,4-dione attenuates atherosclerosis possibly by reducing monocyte recruitment to the lesion. Exp Mol Med 43: 471-478, 2011.
29. Jin CY, Moon DO, Lee KJ, Kim MO, Lee JD, Choi YH, Park YM and Kim GY: Piceatannol attenuates lipopolysaccharide-induced NF-kappaB activation and NF-kappaB-related proinflammatory mediators in BV2 microglia. Pharmacol Res 54: 461-467, 2006.

30. Garden GA and Möller T: Microglia biology in health and disease. J Neuroimmune Pharmacol 1: 127-137, 2006.

31. Sugama S, Takenouchi T, Fujita M, Conti B and Hashimoto M: Differential microglial activation between acute stress and lipopolysaccharide treatment. J Neuroimmunol 207: 24-31, 2009.

32. Schwartz M and Shechter R: Systemic inflammatory cells fight off neurodegenerative disease. Nat Rev Neurol 6: 405-410, 2010.

33. Wright JG and Christman JW: The role of nuclear factor kappa $\mathrm{B}$ in the pathogenesis of pulmonary diseases: implications for therapy. Am J Respir Med 2: 211-219, 2003.

34. Atreya I, Atreya R and Neurath MF: NF-kappaB in inflammatory bowel disease. J Int Med 263: 591-596, 2008.

35. Sebban H and Courtois G: NF-kappaB and inflammation in genetic disease. Biochem Pharmacol 72: 1153-1160, 2006.

36. Madrid LV, Wang CY, Guttridge DC, Schottelius AJ, Baldwin AS Jr and Mayo MW. Akt suppresses apoptosis by stimulating the transactivation potential of the RelA/p65 subunit of NF-kappaB. Mol Cell Biol 20: 1626-1638, 2000.

37. Lee JY, Jhun BS, Oh YT, Lee JH, Choe W, Baik HH, Ha J, Yoon KS, Kim SS and Kang I: Activation of adenosine A3 receptor suppresses lipopolysaccharide-induced TNF-alpha production through inhibition of PI 3-kinase/Akt and NF-kappaB activation in murine BV2 microglial cells. Neurosci Lett 396: 1-6, 2006.

38. Shin WS, Szuba A and Rockson SG: The role of chemokines in human cardiovascular pathology: enhanced biological insights. Atherosclerosis 160: 91-102, 2002.

39. Nam NH: Naturally occurring NF-kappaB inhibitors. Mini Rev Med Chem 6: 945-951, 2006.

40. Luqman S and Pezzuto JM. NFkappaB: a promising target for natural products in cancer chemoprevention. Phytother Res 24: 949-963, 2010.

41. Kim SH, Smith CJ and Van Eldik LJ: Importance of MAPK pathways for microglial pro-inflammatory cytokine IL-1 beta production. Neurobiol Aging 25: 431-439, 2004.

42. Kaminska B, Gozdz A, Zawadzka M, Ellert-Miklaszewska A and Lipko M: MAPK signal transduction underlying brain inflammation and gliosis as therapeutic target. Anat Rec 292: 1902-1913, 2009.

43. Kaminska B: MAPK signalling pathways as molecular targets for anti-inflammatory therapy-from molecular mechanisms to therapeutic benefits. Biochim Biophys Acta 1754: 253-262, 2005.

44. Wei J and Feng J: Signaling pathways associated with inflammatory bowel disease. Recent Pat Inflamm Allergy Drug Discov 4: 105-117, 2010.

45. Pyo H, Jou I, Jung S, Hong S and Joe EH: Mitogen-activated protein kinases activated by lipopolysaccharide and beta-amyloid in cultured rat microglia. Neuroreport 9: 871-874, 1998. 